\title{
Least Squares Analysis of Fission Neutron Standard Fields
}

\author{
Patrick. J. Griffin \\ Sandia National Laboratories ${ }^{1}$ \\ Albuquerque, NM 87185-1146
}

\author{
John G. Williams \\ University of Arizona \\ Tucson, AZ 85721-0119
}

\begin{abstract}
A least squares analysis of fission neutron standard fields has been performed using the latest dosimetry cross sections. Discrepant nuclear data are identified and adjusted spectra for ${ }^{252} \mathrm{Cf}$ spontaneous fission and ${ }^{235} \mathrm{U}$ thermal fission fields are presented.
\end{abstract}

\section{INTRODUCTION}

A recent paper [1] by one of the authors examined the C/E (calculation-to-experimental) cross section ratios for standard and reference benchmark fields [2] and reported on some possible inconsistencies in current nuclear data (cross sections and experimental activities) for the benchmark neutron fields. These fission neutron standard fields are crucial in providing a traceable calibration of the neutron field dosimetry used in the characterization of reactor environments needed for neutron testing of electronics in accordance with ASTM E-722. These neutron fields are also important in making recommendations on the selection of activation cross section evaluations for use in spectrum unfolding in accordance with ASTM E-720 and E721 [3]. This paper expands that analysis and provides a complete generalized least squares analysis of the nuclear data for the standard fission fields. The results of the least squares analysis are studied and some changes in nuclear cross section data are recommended. This analysis provides an update to previous ${ }^{252} \mathrm{Cf}$ fission field work by Mannhart [4] through the use of the latest recommended cross section evaluations [5]. Differences in this analysis from the Mannhart work are examined. The current recommended fission neutron spectra come from a Madland-Nix formalism [6]. This analysis adds activation foil data and refines the current recommendations for the fission neutron spectra and covariance matrices.

ASTM E-720 [3] provides a list of 32 reactions that can be used for neutron spectrum determination for neutron fields used in radiation testing of electronics. Four of these 32 are listed as "not recommended for use at this time" because of large uncertainties or discrepant data. The present paper evaluates a total of 41 reactions, including most of those listed in ASTM E-
720 , and provides current and objective criteria for determining their status.

\section{STANDARD NEUTRON FIELDS AND CATEGORY I REACTIONS}

The concepts of Standard Neutron Fields and Category I neutron reactions for reactor neutron dosimetry were codified at a series of IAEA consultants' meetings held in Vienna in the 1970s. These classifications are still relevant today and are used in this paper as the basis for an assessment of the quality of available representations of the fission field spectra and of the reaction cross sections discussed here. These classifications also provide a convenient method of summarizing and disseminating our conclusions.

A Standard Neutron Field is defined [7] as:

A permanent, stable and reproducible radiation field that is characterized to state-of-the-art accuracy in terms of neutron flux density and energy spectra, and spatial and angular flux distribution. Important field quantities must be verified by interlaboratory measurements.

At the time, the only fast neutron field meeting these requirements was the ${ }^{252} \mathrm{Cf}$ spontaneous fission field. The thermal Maxwellian and epithermal 1/E slowing-down fields were also included as standard fields. The ${ }^{235} \mathrm{U}$ thermal-neutron induced fission field was not included on the grounds that it was less well known than the californium field, over the same energy range, and therefore did not meet the stipulation of "state-ofthe-art accuracy." The same remains true today, although the ${ }^{235} \mathrm{U}$ field does have an important advantage: the possibility of higher neutron density.

A Category I reaction (for reactor neutron dosimetry) is defined [8] as a reaction: (a) for which the energy-dependent cross sections are well known over their response range in standard neutron fields; and (b) for which calculated reaction rates in the standard neutron fields are consistent with the measured

\footnotetext{
${ }^{1}$ Sandia is a multiprogram laboratory operated by Sandia Corporation, a Lockheed Martin Company, for the United States Department of Energy under contract DE-AC04-94AL85000.
} 


\section{DISCLAIMER}

This report was prepared as an account of work sponsored by an agency of the United States Government. Neither the United States Government nor any agency thereof, nor any of their employees, make any warranty, express or implied, or assumes any legal liability or responsibility for the accuracy, completeness, or usefulness of any information, apparatus, product, or process disclosed, or represents that its use would not infringe privately owned rights. Reference herein to any specific commercial product, process, or service by trade name, trademark, manufacturer, or otherwise does not necessarily constitute or imply its endorsement, recommendation, or favoring by the United States Government or any agency thereof. The views and opinions of authors expressed herein do not necessarily state or reflect those of the United States Government or any agency thereof. 


\section{DISCLAMMER}

Portions of this document may be illegible in electronic image products. Images are produced from the best available original document. 
reaction rates. Other reactions used for neutron metrology, not meeting the above criteria, are classified as Category II.

In this paper we shall propose a new list of dosimetry reactions meeting this definition. An important caveat is that our work includes only fast neutron fields and therefore some Category I reactions, important in thermal and epithermal neutron fields, are not included.

\section{LEAST SQUARES ANALYSIS}

A modification of the LSL-M2 code [9] was used for the generalized least squares analysis. The cross sections and the covariance data were taken from the SNLRML compendium [5] which was drawn from several current dosimetry-quality cross section libraries, including the International Atomic Energy Agency (IAEA) recommended IRDF-90 library [10].

A 366-energy group structure was used in this work in order to fully represent the covariance matrices of cross-sections and spectra. The 80-group MATSX11 energy bin structure [11] was a subset of this 366-group structure. In some instances, it was found that erroneous results were obtained when data collapsed into the 80-group set were used to calculate cross section uncertainties. For the cross sections considered here, the 366 group structure is the smallest set that is proved to avoid such errors.

\section{A. $\quad{ }^{252}$ Cf Spontaneous Fission Field}

The ${ }^{252} \mathrm{Cf}$ fission input spectrum is taken from the ENDF/ $\mathrm{B}-\mathrm{VI}$ cross section files (MAT=9861, $\mathrm{MF}=5, \mathrm{MT}=18$ ) [12] which is based on a Madland-Nix formulation. This ENDF file also gives a covariance analysis for this spectrum. Activities are available for more reactions than we have high quality cross sections with covariance matrices. Table 1 lists the available activity data ${ }^{1}$ for which the authors have high quality cross section and uncertainty data in the ${ }^{252} \mathrm{Cf}$ field. The pre-selected experimental points in Table 1 were chosen to represent the latest or lowest-uncertainty, most recent measurement for the given reaction.

The initial LSL analysis for the ${ }^{252} \mathrm{Cf}$ fission field highlighted significant disagreements for the ${ }^{115} \operatorname{In}(n, \gamma){ }^{116 m} \mathrm{In}$, ${ }^{59} \mathrm{Co}(\mathrm{n}, \gamma){ }^{60} \mathrm{Co}$, and ${ }^{46} \mathrm{Ti}(\mathrm{n}, \mathrm{p}){ }^{46} \mathrm{Sc}$ reactions. Unlike in the ${ }^{235} \mathrm{U}$ fission benchmark field which will be discussed in Section IIIB, the ${ }^{64} \mathrm{Zn}(\mathrm{n}, \mathrm{p}){ }^{64} \mathrm{Cu}$ reaction provided consistent results in this field with a $\mathrm{C} / \mathrm{E}$ differing by only $3.6 \%$ from unity and with a uncertainty of $5.3 \%$.

Figure 1 shows the $\mathrm{C} / \mathrm{E}$ ratios for the ${ }^{252} \mathrm{Cf}$ standard field reactions plotted versus the median energy for the reaction response. A visible trend is seen in the $\mathrm{C} / \mathrm{E}$ ratios ( 0.9 for the lowest energies and 1.05 at the highest energies) and is reflected in

1. The references for the selected cross section measurements are available from one of the authors (PJG) upon request. A summary of the selected activity data, including the references, will appear in a Sandia National Laboratories report currently in preparation. the least squares adjustment of the neutron spectrum. This trend suggests that the actual ${ }^{252} \mathrm{Cf}$ neutron field has a softer spectrum than the current ENDF/B-VI evaluated spectra.

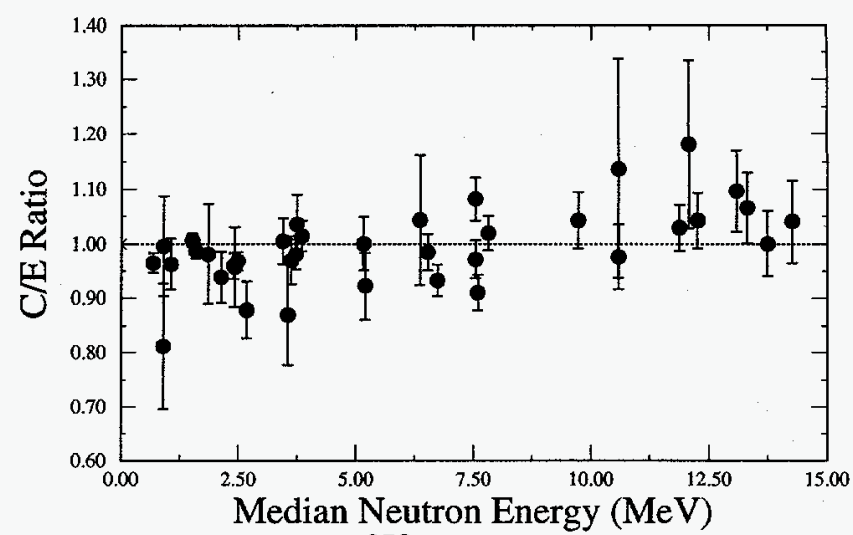

Figure 1: C/E for ${ }^{252} \mathrm{Cf}$ Standard Fission Field

The resolution of the discrepant nuclear data for the three reactions is addressed in the following sections. When the discrepant data for the ${ }^{59} \mathrm{Co}(\mathrm{n}, \gamma){ }^{60} \mathrm{Co}$ and ${ }^{46} \mathrm{Ti}(\mathrm{n}, \mathrm{p}){ }^{46} \mathrm{Sc}$ reactions are eliminated but the correct ${ }^{115} \operatorname{In}\left(n, n^{\prime}\right)^{115 m}$ In branching ratio is included in the least squares analysis, the resulting chisquared per degree of freedom is 1.457 with 37 degrees of freedom. We can reject the null hypothesis that the experimental distribution is inconsistent with the theoretical distributions at the 0.01 level of significance but not at the 0.05 level of significance. Thus this value of chi-squared is large but acceptable. When the recommended changes are made in the cross sections and uncertainties, the chi-squared is 1.51 with 39 degrees of freedom.

\section{1). ${ }^{115} \operatorname{In}(n, \gamma)^{116 m} \operatorname{In}$ Reaction}

A study of the ${ }^{115} \operatorname{In}(n, \gamma)^{116 m}$ In reaction and a comparison with the previous results by Mannhart [4] showed a problem with the cross sections used in our analysis. An error in the IRDF-90 and in the SNLRML, ${ }^{115} \operatorname{In}(n, \gamma){ }^{116 m}$ In cross section duplicated an earlier error in the ENDF/B- $V$ Dosimetry cross section library that was corrected in a 1984 update. The error was caused by the failure to apply the ENDF File 9 branching ratio data for the File 3 cross section data. When this $21 \%$ correction was provided, the ${ }^{115} \operatorname{In}(\mathrm{n}, \gamma)^{116 \mathrm{~m}}$ In reaction data were consistent with the other ${ }^{252} \mathrm{Cf}$ fission field data. The data in Table 1 reflect this correction.

\section{2). ${ }^{59} \mathrm{Co}(n, \gamma){ }^{60} \mathrm{Co}$ Reaction}

Table 2 shows the experimental and calculated data for the ${ }^{59} \mathrm{Co}(\mathrm{n}, \gamma){ }^{60} \mathrm{Co}$ reaction in the ${ }^{252} \mathrm{Cf}$ fission field. The majority of the activity contribution in the ${ }^{252} \mathrm{Cf}$ standard fission field originates in the relatively high energy interval from 0.5 to 3 $\mathrm{MeV}$. Only one experimental datapoint is available for this reaction/field combination. This measurement was made by a very respected, competent experimenter, but it was made over twenty years ago. There is a need for some experimental confirmation of this measurement. This is an action that should be requested from the national laboratories that currently host the 
Table 1: ${ }^{252}$ Cf Fission Neutron Cross Sections for Dosimetry Sensors

\begin{tabular}{|c|c|c|c|c|c|c|c|c|c|}
\hline & \multirow{2}{*}{$\begin{array}{c}\text { Dosimetry } \\
\text { Reaction }\end{array}$} & \multirow{2}{*}{$\begin{array}{c}\text { Median } \\
\text { Response } \\
\text { Energy, } \\
\text { E }_{50} \\
(\mathrm{MeV})\end{array}$} & \multicolumn{3}{|c|}{$\begin{array}{l}{ }^{252} \text { Cf Fission } \\
\text { Cross Section }\end{array}$} & \multicolumn{4}{|c|}{${ }^{252}$ Cf Fission Uncertainty } \\
\hline & & & $\begin{array}{l}\text { Calc. } \\
(\mathrm{mb})\end{array}$ & $\begin{array}{l}\text { Expt. } \\
\text { (mb) }\end{array}$ & C/E & $\begin{array}{c}\text { Spect. } \\
\text { Unc. } \\
\text { (\%) }\end{array}$ & $\begin{array}{l}\text { Xsec. } \\
\text { Unc. } \\
\text { (\%) }\end{array}$ & $\begin{array}{l}\text { Expt. } \\
\text { Unc. } \\
(\%)\end{array}$ & $\begin{array}{l}\text { C/E } \\
\text { Unc } \\
(\%)\end{array}$ \\
\hline 1 & ${ }^{197} \mathrm{Au}(\mathrm{n}, \gamma){ }^{198} \mathrm{Au}$ & 0.7172 & 74.17 & 76.86 & 0.9650 & 0.722 & 0.783 & 1.59 & 1.91 \\
\hline 2 & ${ }^{23} \mathrm{Na}(\mathrm{n}, \gamma){ }^{24} \mathrm{Na}$ & 0.9558 & 0.2717 & 0.3350 & 0.8110 & 0.829 & 13.7 & 4.00 & 14.3 \\
\hline 3 & ${ }^{63} \mathrm{Cu}(\mathrm{n}, \gamma){ }^{64} \mathrm{Cu}$ & 0.9586 & 10.40 & 10.45 & 0.9953 & 0.614 & 8.58 & 3.24 & 9.19 \\
\hline $4^{*}$ & ${ }^{59} \mathrm{Co}(\mathrm{n}, \gamma)^{60} \mathrm{Co}$ & 1.045 & 6.062 & 6.971 & 0.8697 & 0.709 & 4.71 & 5.00 & 6.90 \\
\hline 5 & ${ }^{115} \mathrm{In}(\mathrm{n}, \gamma)^{116 \mathrm{~m}_{\mathrm{In}}}$ & 1.084 & 121.8 & 126.5 & 0.9626 & 0.331 & 4.33 & 2.23 & 4.88 \\
\hline 6 & ${ }^{235} \mathrm{U}(\mathrm{n}, \mathrm{f}) \mathrm{FP}$ & 1.690 & 1218. & 1210. & 1.007 & 0.0764 & 0.319 & 1.20 & 1.24 \\
\hline 7 & ${ }^{239} \mathrm{Pu}(\mathrm{n}, \mathrm{f}) \mathrm{FP}$ & 1.764 & 1789. & 1812. & 0.9876 & 0.0763 & 0.407 & 1.37 & 1.43 \\
\hline 8 & ${ }^{237} \mathrm{~Np}(\mathrm{n}, \mathrm{f}) \mathrm{FP}$ & 2.069 & 1335. & 1361. & 0.9810 & 0.231 & 9.21 & 1.58 & 9.35 \\
\hline 9 & ${ }^{103} \mathrm{Rh}\left(\mathrm{n}, \mathrm{n}^{\prime}\right)^{103 m} \mathrm{Rh}$ & 2.364 & 714.4 & 761.5 & 0.9382 & 0.261 & 3.08 & 4.00 & 5.06 \\
\hline 10 & ${ }^{115} \operatorname{In}\left(n, n^{\prime}\right)^{115 m} \operatorname{In}$ & 2.655 & 189.8 & 197.9 & 0.9591 & 0.378 & 2.16 & 1.30 & 2.55 \\
\hline 11 & ${ }^{93} \mathrm{Nb}\left(\mathrm{n}, \mathrm{n}^{\prime}\right)^{93 \mathrm{~m}} \mathrm{Nb}$ & 2.693 & 142.7 & 150.6 & 0.9475 & 0.355 & 2.99 & 3.00 & 4.25 \\
\hline 12 & ${ }^{238} \mathrm{U}(\mathrm{n}, \mathrm{f}) \mathrm{FP}$ & 2.751 & 315.4 & 325.7 & 0.9684 & 0.398 & 0.535 & 1.63 & 1.76 \\
\hline 13 & ${ }^{232} \mathrm{Th}(\mathrm{n}, \mathrm{f}) \mathrm{FP}$ & 2.977 & 78.53 & 89.40 & 0.8784 & 0.420 & 5.09 & 3.03 & 5.94 \\
\hline 14 & ${ }^{47} \operatorname{Ti}(n, p)^{47} S c$ & 3.826 & 19.38 & 19.29 & 1.005 & 0.619 & 3.78 & 1.66 & 4.18 \\
\hline 15 & ${ }^{31} \mathrm{P}(\mathrm{n}, \mathrm{p})^{31} \mathrm{Si}$ & 3.950 & 30.68 & 35.28 & 0.8695 & 0.694 & 3.56 & 10.0 & 10.6 \\
\hline 16 & ${ }^{32} \mathrm{~S}(\mathrm{n}, \mathrm{p})^{32} \mathrm{P}$ & 4.055 & 70.44 & 72.62 & 0.9699 & 0.747 & 3.68 & 3.50 & 5.13 \\
\hline 17 & ${ }^{58} \mathrm{Ni}(\mathrm{n}, \mathrm{p})^{58} \mathrm{Co}$ & 4.097 & 115.3 & 117.6 & 0.9806 & 0.720 & 2.41 & 1.30 & 2.84 \\
\hline 18 & ${ }^{64} \mathrm{Zn}(\mathrm{n}, \mathrm{p})^{64} \mathrm{Cu}$ & 4.119 & 42.10 & 40.65 & 1.036 & 0.784 & 4.86 & 1.64 & 5.19 \\
\hline 19 & ${ }^{54} \mathrm{Fe}(\mathrm{n}, \mathrm{p}){ }^{54} \mathrm{Mn}$ & 4.259 & 88.13 & 86.88 & 1.014 & 0.783 & 2.09 & 1.34 & 2.60 \\
\hline 20 & ${ }^{59} \mathrm{Co}(\mathrm{n}, \mathrm{p}){ }^{59} \mathrm{Fe}$ & 5.736 & 1.692 & 1.692 & 1.000 & 1.14 & 4.07 & 2.49 & 4.91 \\
\hline 21 & ${ }^{27} \mathrm{Al}(\mathrm{n}, \mathrm{p})^{27} \mathrm{Mg}$ & 5.811 & 4.673 & 5.066 & 0.9225 & 1.15 & 2.91 & 2.14 & 3.79 \\
\hline $22 *$ & ${ }^{46} \mathrm{Ti}(\mathrm{n}, \mathrm{p})^{46} \mathrm{Sc}$ & 5.878 & 12.33 & 14.09 & 0.8751 & 1.18 & 2.47 & 1.76 & 3.26 \\
\hline 23 & ${ }^{60} \mathrm{Ni}(\mathrm{n}, \mathrm{p})^{60} \mathrm{Co}$ & 7.046 & 2.493 & 2.390 & 1.043 & 1.38 & $\overline{10.1}$ & 5.00 & 11.4 \\
\hline 24 & ${ }^{63} \mathrm{Cu}(\mathrm{n}, \alpha){ }^{60} \mathrm{Co}$ & 7.252 & 0.6784 & 0.6891 & 0.9845 & 1.39 & 2.38 & 1.98 & 3.39 \\
\hline 25 & ${ }^{56} \mathrm{Fe}(\mathrm{n}, \mathrm{p})^{56} \mathrm{Mn}$ & 7.520 & 1.370 & 1.469 & 0.9324 & 1.46 & 2.18 & 1.77 & 3.17 \\
\hline 26 & ${ }^{24} \mathrm{Mg}(\mathrm{n}, \mathrm{p}){ }^{24} \mathrm{Na}$ & 8.188 & 2.162 & 1.998 & 1.082 & 1.59 & 2.24 & 2.42 & 3.66 \\
\hline 27 & ${ }^{59} \mathrm{Co}(\mathrm{n}, \alpha)^{56} \mathrm{Mn}$ & 8.318 & 0.2161 & 0.2225 & 0.9714 & 1.57 & 2.73 & 1.86 & 3.65 \\
\hline 28 & ${ }^{48} \mathrm{Ti}(\mathrm{n}, \mathrm{p})^{48} \mathrm{Sc}$ & 8.362 & 0.3871 & 0.4252 & 0.9104 & 1.58 & 2.58 & 1.89 & 3.57 \\
\hline 29 & ${ }^{27} \mathrm{Al}(\mathrm{n}, \alpha){ }^{24} \mathrm{Na}$ & 8.603 & 1.037 & 1.017 & 1.020 & 1.63 & 2.15 & 1.47 & 3.07 \\
\hline 30 & ${ }^{197} \mathrm{Au}(\mathrm{n}, 2 \mathrm{n}){ }^{196} \mathrm{Au}$ & 10.54 & 5.744 & 5.509 & 1.043 & 2.04 & 4.14 & 1.83 & 4.96 \\
\hline 31 & ${ }^{127} I(n, 2 n)^{126} I$ & 11.51 & 2.356 & 2.071 & 1.137 & 2.32 & 17.2 & 2.75 & 17.6 \\
\hline 32 & ${ }^{93} \mathrm{Nb}(\mathrm{n}, 2 \mathrm{n})^{92 \mathrm{~m}} \mathrm{Nb}$ & 11.53 & 0.7311 & 0.7490 & 0.9761 & 2.32 & 2.53 & 5.07 & 6.12 \\
\hline 33 & ${ }^{65} \mathrm{Cu}(n, 2 n){ }^{64} \mathrm{Cu}$ & 12.59 & 0.6782 & 0.6590 & 1.029 & 2.94 & 1.83 & 2.24 & 4.13 \\
\hline 34 & ${ }^{55} \mathrm{Mn}(\mathrm{n}, 2 \mathrm{n}){ }^{54} \mathrm{Mn}$ & 12.81 & 0.4816 & 0.4077 & 1.181 & 3.10 & 12.4 & 2.34 & 13.0 \\
\hline 35 & ${ }^{59} \mathrm{Co}(n, 2 n)^{58} \mathrm{Co}$ & 12.98 & 0.4228 & 0.4056 & 1.042 & 3.28 & 2.61 & 2.52 & 4.89 \\
\hline 36 & ${ }^{63} \mathrm{Cu}(n, 2 n)^{62} \mathrm{Cu}$ & 13.76 & 0.2095 & 0.1912 & 1.096 & 4.15 & 4.06 & 3.89 & 6.99 \\
\hline 37 & ${ }^{19} F(n, 2 n)^{18} F$ & 13.94 & 0.01726 & 0.01619 & 1.066 & 4.42 & 2.64 & 3.40 & 6.17 \\
\hline 38 & ${ }^{90} \mathrm{Zr}(\mathrm{n}, 2 \mathrm{n})^{89} \mathrm{Zr}$ & 14.36 & 0.2212 & 0.2212 & 1.000 & 5.13 & 1.56 & 2.90 & 6.09 \\
\hline 39 & ${ }^{58} \mathrm{Ni}(\mathrm{n}, 2 \mathrm{n})^{57} \mathrm{Ni}$ & 14.93 & 0.009258 & 0.008897 & 1.041 & 6.13 & 2.49 & 3.59 & 7.53 \\
\hline
\end{tabular}

benchmark ${ }^{252} \mathrm{Cf}$ fields. The U.S. ${ }^{252} \mathrm{Cf}$ standard benchmark field is at the National Institute of Standards and Technology (NIST).

A review of the documentation on the ENDF/B-VI evaluation, discussions with one of the principal evaluators, and the observed discrepancies between the high energy part of the JENDL 3.2 and ENDF/B-VI cross sections leads the authors to recommend increasing the uncertainty on the high energy portion of the reaction cross section. The modified uncertainties are approximately double the original values and are set at $20 \%$ from $0.8-6 \mathrm{MeV}$ and at $50 \%$ above $6 \mathrm{MeV}$. 


\section{3). ${ }^{46} T i(n, p){ }^{46} S c$ Reaction}

Table 3 shows the experimental and calculated data for the ${ }^{46} \mathrm{Ti}(\mathrm{n}, \mathrm{p}){ }^{46} \mathrm{Sc}$ reaction. Again this reaction had an acceptable $\mathrm{C} / \mathrm{E}$ agreement for the Mannhart analysis when the ENDF/B-V Dosimetry library was used. When the latest, supposedly higher fidelity, GLUCS-93 [13] or IRDF-90 cross sections are used, the agreement is poor, while the cross section contribution to the spectrum-averaged uncertainty is decreased by a factor of five. The recent measured cross section values are fairly consistent. The experimental data are not an obvious source of the data discrepancy.

The GLUCS analysis [13] is based on a very high fidelity least squares analysis of existing cross section data and used the ENDF/B-V Dosimetry cross section as the a priori cross section. Thus this evaluation can not easily be dismissed. An inspection of the evaluations summarized in Table 3 indicates that the GLUCS evaluation decreased the cross section uncertainty by substantial amounts. This seems to be the most suspect component in the ${ }^{46} \mathrm{Ti}(\mathrm{n}, \mathrm{p}){ }^{46} \mathrm{Sc}$ analysis. The authors are contacting the GLUCS evaluators to obtain information on whether and how the benchmark integral data were considered in their analysis. In the interim, the authors recommendation is to keep the GLUCS cross section, but to use the ENDF/B-V Dosimetry covariance matrix - the a priori data for the GLUCS analysis. The rationale is that the some conflicting integral data were not included in the GLUCS least squares analysis, resulting in an unrealistically small covariance for this reaction.

Table 2: ${ }^{59} \mathrm{Co}(n, \gamma){ }^{60} \mathrm{Co}$ Cross Section in the ${ }^{252} \mathrm{Cf}$ Fission Field

\begin{tabular}{|c|c|c|c|}
\hline \multicolumn{2}{|c|}{ Experimental } & \multicolumn{2}{c|}{ Calculational } \\
\hline Source & $\begin{array}{c}\text { Xsec } \\
(\mathbf{m b})\end{array}$ & Source & $\begin{array}{c}\text { Xsec } \\
(\mathbf{m b})\end{array}$ \\
\hline Deszo, 1977 & $6.97(4.88 \%)$ & IRDF-90 & $6.06(4.7 \%)$ \\
\cline { 3 - 4 } & & JENDL-dos & $5.17(4.2 \%)$ \\
\cline { 3 - 4 } & & JEF 2.2 & 4.78 \\
\cline { 3 - 4 } & & E5 Dosimetry & $6.06(4.7 \%)$ \\
\cline { 3 - 4 } & & E6, r1 & 4.78 \\
\cline { 3 - 4 } & & E6, r2 & 4.86 \\
\hline
\end{tabular}

Table 3: ${ }^{46} \mathrm{Ti}(\mathrm{n}, \mathrm{p}){ }^{46} \mathrm{Sc}$ Reaction in the ${ }^{252} \mathrm{Cf}$ Fission Field

\begin{tabular}{|c|c|c|c|}
\hline \multicolumn{2}{|c|}{ Experimental } & \multicolumn{2}{c|}{ Calculational } \\
\hline Source & $\begin{array}{c}\text { Xsec } \\
(\mathbf{m b})\end{array}$ & Source & $\begin{array}{c}\text { Xsec } \\
(\mathbf{m b})\end{array}$ \\
\hline Kirouc, 1973 & $12.4(9.7 \%)$ & GLUCS-93 & $12.6(2.45 \%)$ \\
\hline Alberts, 1975 & $13.8(2.17 \%)$ & GLUCS-90 & $12.3(2.94 \%)$ \\
\hline Dezso, 1977 & $13.4(8.21 \%)$ & IRDF-82 & $13.2(12.6 \%)$ \\
\hline Spiegel, 1978 & $15.0(6.67 \%)$ & IRDF-90 & $12.3(2.45 \%)$ \\
\hline Dezso, 1983 & $13.6(8.9 \%)$ & JENDL-dos & $12.3(12.6 \%)$ \\
\hline Kimura, 1986 & $14.04(4.36 \%)$ & E5 Dosimetry & $13.2(12.6 \%)$ \\
\hline Mannhart,1989 & $14.09(1.76 \%)$ & ENDF/B-VI & $13.2(12.6 \%)$ \\
\hline
\end{tabular}

\section{B. $\quad{ }^{235} U$ Thermal Fission Field}

The ${ }^{235} \mathrm{U}$ fission input spectrum is taken from the ENDF/ B-VI cross section files [12] $(\mathrm{MAT}=9228, \mathrm{MF}=5, \mathrm{MT}=18)$ which is based on a Madland-Nix formulation. Since the ENDF files did not give a covariance analysis for this spectrum, a coarse energy group covariance matrix was taken from the work by Petilli and Gilliam [14]. The Petilli work resulted in a spec- trum that was, within the coarse group structure, identical to the ENDF ${ }^{235} \mathrm{U}$ fission neutron spectrum.

The LSL analysis, using all of the available activities except the ${ }^{64} \mathrm{Zn}(\mathrm{n}, \mathrm{p}){ }^{64} \mathrm{Cu}$ reaction, provided a chi-squared per degree of freedom of 1.295 and had 35 degrees of freedom. This value of the chi-squared per degree of freedom shows good agreement between the uncertainty estimates and the values for the input data. The ${ }^{64} \mathrm{Zn}(\mathrm{n}, \mathrm{p}){ }^{64} \mathrm{Cu}$ reaction was eliminated from the analysis since its $\mathrm{C} / \mathrm{E}$ disagreed by more than three standard deviations. The authors are not aware of any previous least squares analysis for this benchmark field which used more reactions than the four fission reactions considered in the Petilli [14] work. Thus there is no previous detailed analysis to compare with these results.

The cross section and uncertainty data in this field are presented in Table 4 . Figure 2 shows the $\mathrm{C} / \mathrm{E}$ activity ratios and the associated uncertainties. A visual inspection of this figure confirms the general good agreement in the data and associated uncertainty and the absence of any energy-dependence in the $\mathrm{C} / \mathrm{E}$ ratios.

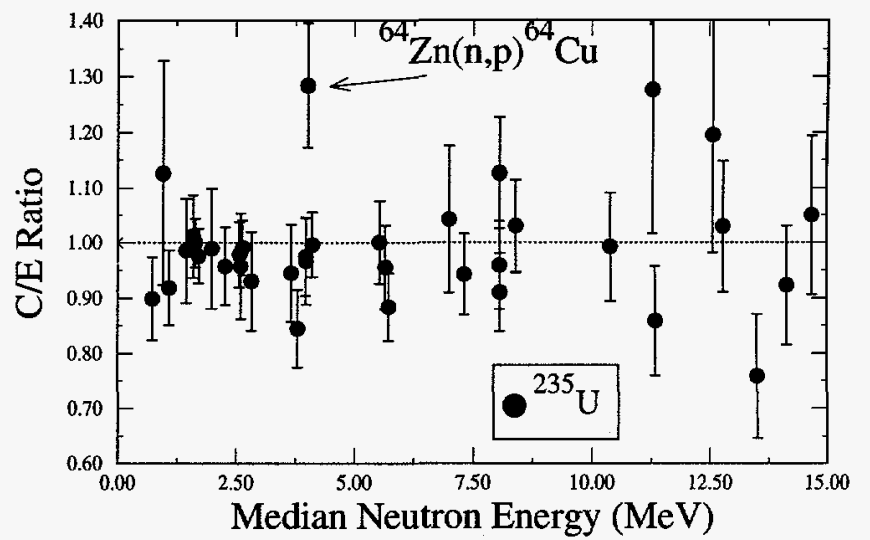

Figure 2: C/E for ${ }^{235} \mathrm{U}$ Standard Fission Field

1). ${ }^{64} \mathrm{Zn}(n, p){ }^{64} \mathrm{Cu}$ Reaction

The SNLRML-recommended ${ }^{64} \mathrm{Zn}(\mathrm{n}, \mathrm{p}){ }^{64} \mathrm{Cu}$ cross section is an IRK evaluation first reported in the IRDF-90 library. An inspection of available ${ }^{64} \mathrm{Zn}(\mathrm{n}, \mathrm{p}){ }^{64} \mathrm{Cu}$ cross section evaluations suggested that part of the problem presented by the large $\mathrm{C} / \mathrm{E}$ value resides in an underestimation of the cross section uncertainty. Figure 3 shows the cross section uncertainty while Figure 4 shows the observed variation in current dosimetryquality cross section evaluations. The LSL analysis highlighted the $\mathrm{C} / \mathrm{E}$ disagreement for this field, and the current cross sections emphasize the need to examine the details used to support the ${ }^{64} \mathrm{Zn}(\mathrm{n}, \mathrm{p})^{64} \mathrm{Cu}$ covariance estimate. The $3 \%$ uncertainty reflected in the covariance file for the cross section at $5 \mathrm{MeV}$ is at odds with the $21 \%$ discrepancy seen between the IRDF-90 and JENDL Dosimetry evaluations. Both evaluations were performed in 1990 and, despite the similarity of the JENDL and the older IRDF-82 cross section, the JENDL evaluation appears to be an independent evaluation. 
Table 4: ${ }^{235} \mathrm{U}$ Thermal Fission Neutron Cross Sections for Dosimetry Sensors

\begin{tabular}{|c|c|c|c|c|c|c|c|c|c|}
\hline & \multirow{2}{*}{$\begin{array}{l}\text { Dosimetry } \\
\text { Reaction }\end{array}$} & \multirow{2}{*}{$\begin{array}{c}\text { Median } \\
\text { Response } \\
\text { Energy, } \\
\text { E }_{50} \\
\text { (MeV) }\end{array}$} & \multicolumn{3}{|c|}{$\begin{array}{c}{ }^{235} \text { U Thermal Fission } \\
\text { Cross Section }\end{array}$} & \multicolumn{4}{|c|}{${ }^{352}$ U Thermal Fission Uncertainty } \\
\hline & & & $\begin{array}{l}\text { Calc. } \\
\text { (mb) }\end{array}$ & $\begin{array}{l}\text { Expt. } \\
\text { (mb) }\end{array}$ & C/E & $\begin{array}{l}\text { Spect. } \\
\text { Unc. } \\
(\%)\end{array}$ & $\begin{array}{l}\text { Xsec. } \\
\text { Unc. } \\
(\%)\end{array}$ & $\begin{array}{l}\text { Expt. } \\
\text { Unc. } \\
(\%)\end{array}$ & $\begin{array}{l}\text { C/E } \\
\text { Unc. } \\
(\%)\end{array}$ \\
\hline 1 & ${ }^{197} \mathrm{Au}(\mathrm{n}, \gamma){ }^{198} \mathrm{Au}$ & 0.7362 & 75.04 & 83.50 & 0.8987 & 5.76 & 0.780 & 6.00 & 8.35 \\
\hline 2 & ${ }^{63} \mathrm{Cu}(\mathrm{n}, \gamma)^{64} \mathrm{Cu}$ & 0.9601 & 10.48 & 9.304 & 1.126 & 4.74 & 8.66 & 15.0 & 18.0 \\
\hline 3 & ${ }^{115} \operatorname{In}(n, \gamma){ }^{116 m_{I n}}$ & 1.090 & 124.4 & 135.4 & 0.9185 & 4.44 & 4.36 & 4.00 & 7.40 \\
\hline 4 & ${ }^{10} \mathrm{~B}(\mathrm{n}, \mathrm{X}){ }^{4} \mathrm{He}$ & 1.448 & 532.4 & 540.0 & 0.9859 & 5.43 & 6.83 & 4.07 & 9.63 \\
\hline 5 & ${ }^{6} \mathrm{Li}(\mathrm{n}, \mathrm{X})^{4} \mathrm{He}$ & 1.594 & 460.3 & 455.0 & 1.012 & 5.83 & 2.45 & 3.96 & 7.46 \\
\hline 6 & ${ }^{235} \mathrm{U}(\mathrm{n}, \mathrm{f}) \mathrm{FP}$ & 1.642 & 1216. & 1216. & 0.9999 & 4.09 & 0.319 & 1.60 & 4.41 \\
\hline 7 & ${ }^{239} \mathrm{Pu}(\mathrm{n}, \mathrm{f}) \mathrm{FP}$ & 1.710 & 1788. & 1832. & 0.9762 & 4.06 & 0.408 & 3.00 & 5.07 \\
\hline 8 & ${ }^{237} \mathrm{~Np}(\mathrm{n}, \mathrm{f}) \mathrm{FP}$ & 1.987 & 1330. & 1344. & 0.9897 & 4.31 & 9.34 & 4.00 & 11.0 \\
\hline 9 & ${ }^{103} \mathrm{Rh}\left(\mathrm{n}, \mathrm{n}^{\prime}\right)^{103 \mathrm{~m}_{\mathrm{Rh}}}$ & 2.272 & 706.0 & 737.4 & 0.9574 & 4.14 & 3.10 & 5.20 & 7.34 \\
\hline 10 & ${ }^{115 \mathrm{In}\left(\mathrm{n}, \mathrm{n}^{\prime}\right)^{115 m} \mathrm{In}}$ & 2.571 & 186.3 & 190.5 & 0.9782 & 4.19 & 2.16 & 3.84 & 6.08 \\
\hline 11 & ${ }^{93} \mathrm{Nb}\left(\mathrm{n}, \mathrm{n}^{\prime}\right)^{93 m_{\mathrm{Nb}}}$ & 2.600 & 140.0 & 146.4 & 0.9563 & 4.14 & 3.01 & 3.00 & 5.93 \\
\hline 12 & ${ }^{238} \mathrm{U}(\mathrm{n}, \mathrm{f}) \mathrm{FP}$ & 2.638 & 306.2 & 309.0 & 0.9910 & 4.23 & 0.535 & 2.60 & 4.99 \\
\hline 13 & ${ }^{232} \mathrm{Th}(\mathrm{n}, \mathrm{f}) \mathrm{FP}$ & 2.826 & 75.33 & 81.00 & 0.9300 & 4.15 & 5.11 & 7.00 & 9.61 \\
\hline 14 & ${ }^{47} \mathrm{Ti}(\mathrm{n}, \mathrm{p})^{47} \mathrm{Sc}$ & 3.664 & 17.95 & 19.00 & 0.9449 & 4.27 & 3.77 & 7.40 & 9.34 \\
\hline 15 & ${ }^{31} \mathrm{P}(n, p){ }^{31} \mathrm{Si}$ & 3.800 & 28.36 & 33.57 & 0.8448 & 4.60 & 3.56 & 6.00 & 8.36 \\
\hline 16 & ${ }^{58} \mathrm{Ni}(\mathrm{n}, \mathrm{p})^{58} \mathrm{Co}$ & 3.970 & 105.7 & 108.5 & 0.9742 & 4.53 & 2.44 & 5.00 & 7.17 \\
\hline 17 & ${ }^{32} S(n, p){ }^{32} p$ & 3.975 & 64.69 & 66.90 & 0.9669 & 4.89 & 3.63 & 5.40 & 8.14 \\
\hline $18^{*}$ & ${ }^{64} \mathrm{Zn}(\mathrm{n}, \mathrm{p})^{64} \mathrm{Cu}$ & 4.014 & 38.40 & 29.9 & 1.284 & 4.84 & 4.80 & 5.35 & 8.67 \\
\hline 19 & ${ }^{54} \mathrm{Fe}(\mathrm{n}, \mathrm{p}){ }^{54} \mathrm{Mn}$ & 4.106 & 80.18 & 80.46 & 0.9965 & 4.71 & 2.12 & 2.86 & 5.90 \\
\hline 20 & ${ }^{59} \mathrm{Co}(\mathrm{n}, \mathrm{p})^{59} \mathrm{Fe}$ & 5.522 & 1.412 & 1.410 & 1.001 & 5.21 & 4.10 & 3.55 & 7.52 \\
\hline 21 & ${ }^{27} \mathrm{Al}(\mathrm{n}, \mathrm{p}){ }^{27} \mathrm{Mg}$ & 5.645 & 3.913 & 4.096 & 0.9554 & 5.29 & 3.01 & 5.06 & 7.91 \\
\hline 22 & ${ }^{46} \mathrm{Ti}(\mathrm{n}, \mathrm{p})^{46} \mathrm{Sc}$ & 5.715 & 10.25 & 11.60 & 0.8838 & 5.41 & 2.48 & 3.45 & 6.87 \\
\hline 23 & ${ }^{63} \mathrm{Cu}(\mathrm{n}, \alpha)^{60} \mathrm{Co}$ & 6.990 & 0.5211 & 0.5000 & 1.042 & 5.96 & 2.36 & 11.0 & 12.7 \\
\hline 24 & ${ }^{56} \mathrm{Fe}(\mathrm{n}, \mathrm{p})^{56} \mathrm{Mn}$ & 7.308 & 1.029 & 1.092 & 0.9424 & 6.53 & 2.26 & 3.67 & 7.82 \\
\hline 25 & ${ }^{59} \mathrm{Co}(\mathrm{n}, \alpha){ }^{56} \mathrm{Mn}$ & 8.051 & 0.1548 & 0.1614 & 0.9588 & 6.45 & 2.80 & 4.35 & 8.27 \\
\hline 26 & ${ }^{24} \mathrm{Mg}(\mathrm{n}, \mathrm{p}){ }^{24} \mathrm{Na}$ & 8.054 & 1.553 & 1.380 & 1.126 & 6.95 & 2.33 & 5.10 & 8.93 \\
\hline 27 & ${ }^{48} \mathrm{Ti}(\mathrm{n}, \mathrm{p})^{48} \mathrm{Sc}$ & 8.057 & 0.2748 & 0.3020 & 0.9101 & 6.52 & 2.56 & 3.31 & 7.74 \\
\hline 28 & ${ }^{27} \mathrm{Al}(\mathrm{n}, \alpha){ }^{24} \mathrm{Na}$ & 8.399 & 0.7272 & 0.7060 & 1.030 & 6.82 & 2.19 & 3.97 & 8.19 \\
\hline 29 & ${ }^{197} \mathrm{Au}(\mathrm{n}, 2 \mathrm{n}){ }^{196} \mathrm{Au}$ & 10.40 & 3.472 & 3.499 & 0.9923 & 8.13 & 4.33 & 3.71 & 9.93 \\
\hline 30 & ${ }^{127} I(n, 2 n)^{126} I$ & 11.30 & 1.327 & 1.040 & 1.276 & 8.81 & 17.2 & 6.19 & 20.3 \\
\hline 31 & ${ }^{93} \mathrm{Nb}(\mathrm{n}, 2 \mathrm{n})^{92 \mathrm{~m}} \mathrm{Nb}$ & 11.35 & 0.4116 & 0.4796 & 0.8583 & 9.41 & 2.72 & 6.10 & 11.5 \\
\hline 32 & ${ }^{55} \mathrm{Mn}(\mathrm{n}, 2 \mathrm{n})^{54} \mathrm{Mn}$ & 12.58 & 0.2413 & 0.2019 & 1.195 & 10.7 & 13.5 & 5.00 & 17.9 \\
\hline 33 & ${ }^{59} \mathrm{Co}(n, 2 n)^{58} \mathrm{Co}$ & 12.80 & 0.2079 & 0.2020 & 1.029 & 10.7 & 2.91 & 2.97 & 11.5 \\
\hline 34 & ${ }^{63} \mathrm{Cu}(\mathrm{n}, 2 \mathrm{n})^{62} \mathrm{Cu}$ & 13.52 & 0.09586 & 0.1264 & 0.7584 & 9.93 & 4.73 & 9.84 & 14.8 \\
\hline 35 & ${ }^{90} \mathrm{Zr}(\mathrm{n}, 2 \mathrm{n})^{89} \mathrm{Zr}$ & 14.15 & 0.09506 & 0.1030 & 0.9229 & 10.8 & 1.63 & 3.88 & 11.6 \\
\hline 36 & ${ }^{58} \mathrm{Ni}(\mathrm{n}, 2 \mathrm{n}){ }^{57} \mathrm{Ni}$ & 14.68 & 0.00378 & 0.0036 & 1.050 & 11.5 & 2.55 & 7.00 & 13.7 \\
\hline
\end{tabular}

There are two experimental datapoints for this reaction in the ${ }^{235} \mathrm{U}$ thermal standard fission field. These measurements were performed circa 1978 and both quote a measurement uncertainty of about $5 \%$; they disagree by $11 \%$. The experimenters had exchanged results and details of the measurement, and agreed that more work was needed to resolve the disagreement. Since the ${ }^{64} \mathrm{Cu}$ residual nucleus has a very low gamma yield and since the ${ }^{235} \mathrm{U}$ thermal fission field has a low fluence rate while

the decay half-life is $12.7 \mathrm{~h}$, the dosimetry measurements were done using the $\beta^{+}$annihilation radiation. Problems with detector calibration or trace activity from contaminant material may have affected the measurements.

In summary, the integral cross section measurement should be confirmed and the uncertainties on both the measurement and the evaluated cross section should be increased. If we 
use the average of the two measurements and assume a measurement uncertainty of $11 \%$ (which represents the difference between the measurements), then the $\mathrm{C} / \mathrm{E}$ for this reaction is $1.22 \pm 13 \%$. These data are still marginal.
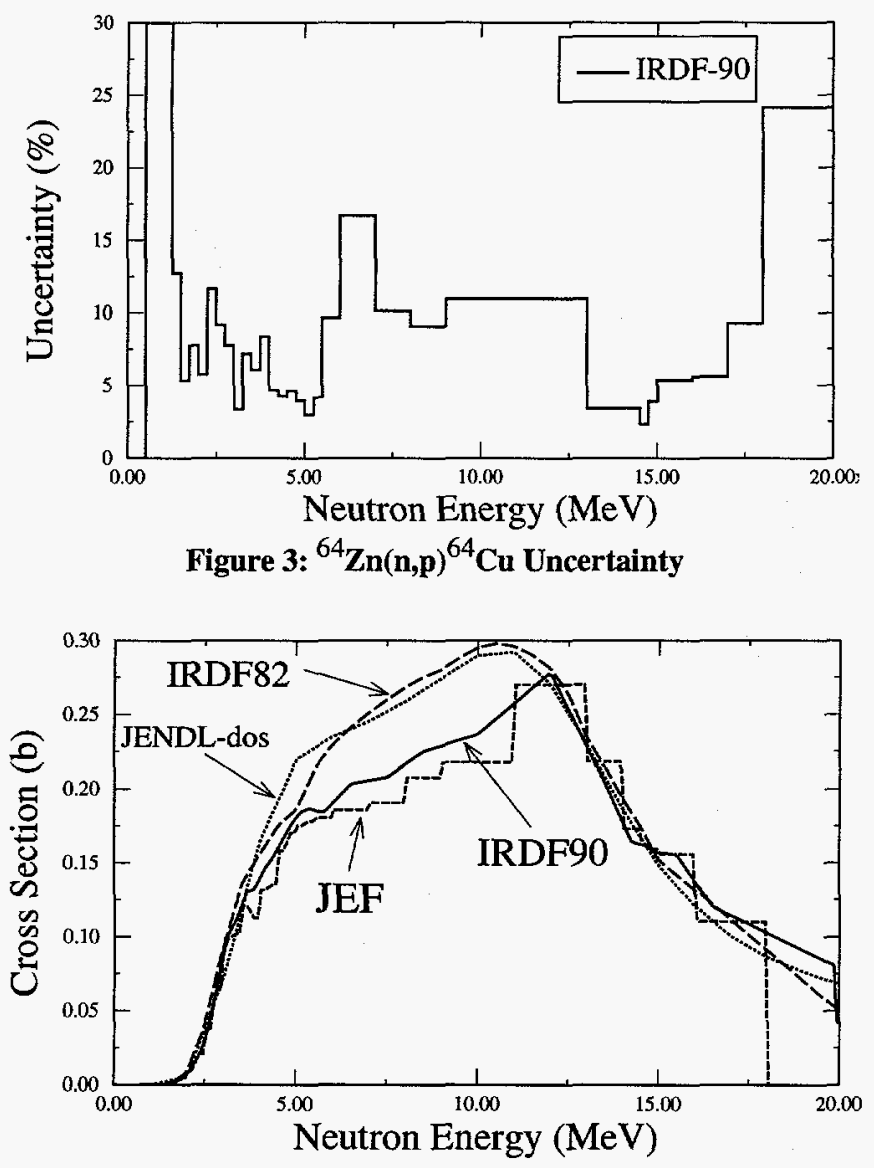

Figure 4: Variation in ${ }^{64} \mathrm{Zn}(\mathrm{n}, \mathrm{p}){ }^{64} \mathrm{Cu}$ Cross Section

\section{RESULTS}

The least squares analysis presented in this paper provided adjusted fission spectra. Figure 5 shows the resulting adjustment in the a priori standard fission field spectra. The same MATSX11 superset energy grid was used in both LSL calculations. The coarser bin structure on the recommended adjustment for the ${ }^{235} \mathrm{U}$ field neutron spectra is attributed to the coarse bin structure in the ${ }^{235} \mathrm{U}$ input spectrum covariance matrix which forced a correlation within broad energy ranges.

The trend in the $\mathrm{C} / \mathrm{E}$ ratios for the ${ }^{252} \mathrm{Cf}$ field that was highlighted in the Section IIIA discussion is seen to result, as expected, in a significant softening in the high energy component $\left(>12 \mathrm{MeV}\right.$ ) of the ${ }^{252} \mathrm{Cf}$ neutron spectrum.

The LSL adjusted ${ }^{252} \mathrm{Cf}$ spectrum uncertainty is nearly identical to the input uncertainty, so the inclusion of the integral cross section data may have improved the baseline spectrum representation but did not significantly decrease the ${ }^{252} \mathrm{Cf}$ spectrum uncertainty.

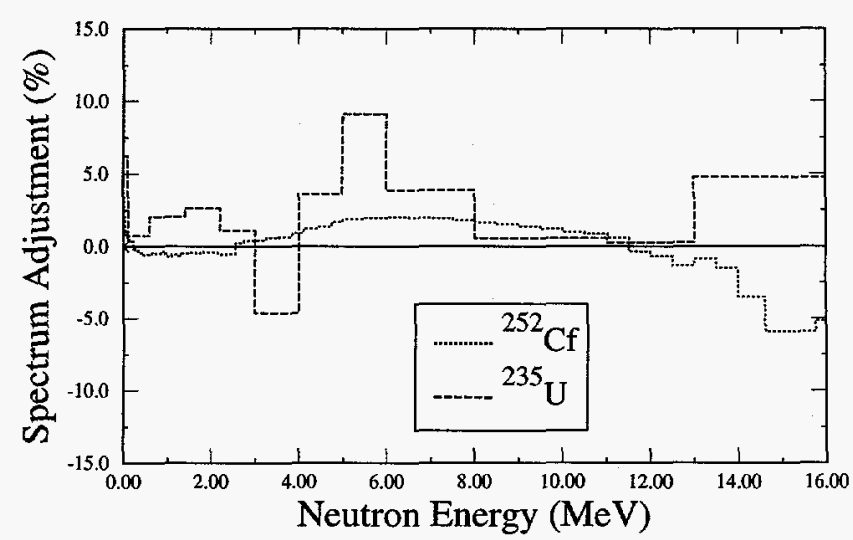

Figure 5: Adjustment of Standard Fission Spectra

The ${ }^{235} \mathrm{U}$ spectrum adjustment is also shown in Figure 5. This adjustment is consistent with the initial spectrum uncertainty estimates presented in Figure 6. A comparison of the original and adjusted ${ }^{235} \mathrm{U}$ uncertainty estimates in Figure 6 showed that the inclusion of the activity data provided a substantial decrease in the spectrum uncertainty in the $100 \mathrm{keV}$ to $10 \mathrm{MeV}$ region. For energies below $100 \mathrm{keV}$, the initial and final energy-dependent uncertainties were nearly identical. This is consistent with the high median energies shown in Table 4 for all of the reaction data used in the LSL analysis.

A regression analysis was performed on the LSL-recommended activity adjustment using the median reaction response energy as the independent variable. For the ${ }^{235} \mathrm{U}$ spectrum there was a negligible correlation $(-5 \%)$ between the median energy and the activity adjustment, and the regression analysis slope and intercept deviated from zero by much less than one standard deviation (slope $=-0.0008 \pm 0.0016$, intercept $=0.000038 \pm$ 0.082 ). Thus there was no apparent trend in the activity adjustment process. For the ${ }^{252} \mathrm{Cf}$ neutron spectrum, however, there was a $38 \%$ correlation between the median energy and the activity adjustment, and the linear model parameters differed significantly from zero (slope $=0.0024 \pm 0.0013$, intercept $=$ $0.025 \pm 0.079$ ). This regression analysis provides additional support for the conclusion that the ENDF/B-VI ${ }^{252} \mathrm{Cf}$ spectrum was too hard.

This paper has fixed an error in the current ${ }^{115} \operatorname{In}(\mathrm{n}, \gamma)^{116 \mathrm{~m}} \mathrm{In}$ dosimetry cross section. It has also highlighted problems with the ${ }^{59} \mathrm{Co}(\mathrm{n}, \gamma){ }^{60} \mathrm{Co}$ and ${ }^{46} \mathrm{Ti}(\mathrm{n}, \mathrm{p}){ }^{46} \mathrm{Sc}$ cross sections that are best remedied by increasing the cross section uncertainty. The need for new experimental measurements on the ${ }^{64} \mathrm{Zn}(\mathrm{n}, \mathrm{p}){ }^{64} \mathrm{Cu}$ and ${ }^{59} \mathrm{Co}(\mathrm{n}, \gamma){ }^{60} \mathrm{Co}$ integral cross sections in the fission benchmark fields is identified as an important input to aid in resolving the discrepant nuclear data. The quality of the ${ }^{64} \mathrm{Zn}(\mathrm{n}, \mathrm{p}){ }^{64} \mathrm{Cu}$ evaluated cross section is unclear and remains under investigation.

The changes in the nuclear data recommended here will be incorporated into the next release (version 2.0) of the SNLRML cross section compendium [4] which is distributed through the Radiation Safety Information Computational Center (RSICC) 
at Oak Ridge National Laboratory. The LSL analysis has also provided adjusted standard fission neutron spectra and associated spectrum covariance matrices. These spectra and covariance matrices, in an 80-group energy structure, have been incorporated into the SNLRML compendium and are available upon request.

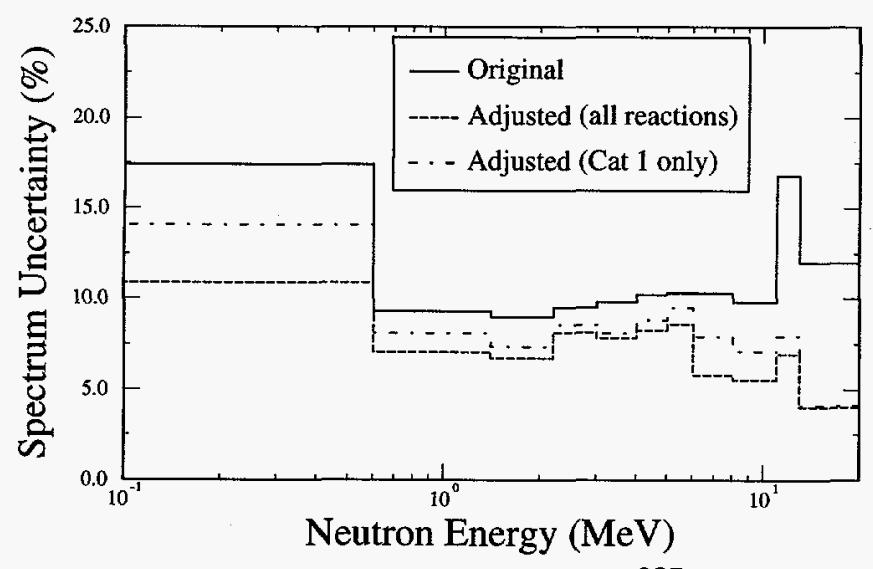

Figure 6: Uncertainty in Prior and Adjusted ${ }^{235} \mathrm{U}$ Standard Fission Spectra

\section{UPDATED NUCLEAR DATA AND CATEGORY I LISTING}

Based on the results of this analysis, a foundation has been provided for a revised list of the Category I reactions recommended for use in reactor neutron dosimetry. Our selection is based on the following numerical interpretation of the definitions quoted at the beginning of this paper. "Cross sections ... well known over the response range" is taken to mean that the calculated uncertainty attributable to cross sections, for the ${ }^{252} \mathrm{Cf}$ field (see Table 1), is less than or equal to $4 \%$. "Calculated reaction rates .... consistent with reaction rates" we take to mean that the C/E ratio for the ${ }^{252} \mathrm{Cf}$ field is equal to unity within 1.5 standard deviations (SD) of its uncertainty (last column of Table 1). We also have imposed the additional requirement that the measured integral cross section in the ${ }^{252} \mathrm{Cf}$ field is known to $4 \%$ or better ("Expt.Unc." in Table 1). An exception to these selection criteria is made for ${ }^{197} \mathrm{Au}(\mathrm{n}, \gamma)$, which just fails the consistency criterion, because its main importance is in thermal and epithermal neutron fields. An additional consideration in this extension was that the ${ }^{197} \mathrm{Au}(\mathrm{n}, \gamma)$ reaction is an IAEA and ENDF Cross Section Evaluation Working Group (CSEWG) standard cross section for energies from $0.1 \mathrm{MeV}$ to $3.5 \mathrm{MeV}$. It should also be borne in mind that other non-threshold reactions should also probably be added on the basis of the thermal Maxwellian and 1/E low energy standard fields.

Our revised list of Category I reactions, obtained by inspection of Table 1, is as follows: ${ }^{197} \mathrm{Au}(\mathrm{n}, \gamma),{ }^{235} \mathrm{U}(\mathrm{n}, \mathrm{f})$, ${ }^{239} \mathrm{Pu}(\mathrm{n}, \mathrm{f}),{ }^{103} \mathrm{Rh}\left(\mathrm{n}, \mathrm{n}^{\prime}\right),{ }^{93} \mathrm{Nb}\left(\mathrm{n}, \mathrm{n}^{\prime}\right),{ }^{47} \mathrm{Ti}(\mathrm{n}, \mathrm{p}),{ }^{32} \mathrm{~S}(\mathrm{n}, \mathrm{p})$, ${ }^{58} \mathrm{Ni}(\mathrm{n}, \mathrm{p}),{ }^{54} \mathrm{Fe}(\mathrm{n}, \mathrm{p}),{ }^{63} \mathrm{Cu}(\mathrm{n}, \alpha),{ }^{59} \mathrm{Co}(\mathrm{n}, \alpha),{ }^{27} \mathrm{Al}(\mathrm{n}, \alpha)$, ${ }^{65} \mathrm{Cu}(\mathrm{n}, 2 \mathrm{n}),{ }^{59} \mathrm{Co}(\mathrm{n}, 2 \mathrm{n}),{ }^{19} \mathrm{~F}(\mathrm{n}, 2 \mathrm{n}),{ }^{90} \mathrm{Zr}(\mathrm{n}, 2 \mathrm{n})$, and ${ }^{58} \mathrm{Ni}(\mathrm{n}, 2 \mathrm{n})$.
In many respects this new list is very satisfactory. More reactions can be included than was the case twenty years ago; seventeen instead of eight. Notable is the good representation of high energy reactions, which previously required the criteria to be somewhat less stringent if any were to be included. A number of the new Category I reactions $\left[{ }^{58} \mathrm{Ni}(\mathrm{n}, \mathrm{p}),{ }^{32} \mathrm{~S}(\mathrm{n}, \mathrm{p})\right.$, ${ }^{54} \mathrm{Fe}(\mathrm{n}, \mathrm{p})$, and $\left.{ }^{59} \mathrm{Co}(\mathrm{n}, \alpha)\right]$ were previously considered to be Category I candidates [15]. This work validates their inclusion.

Zijp [16] has suggested that the Category I reactions be used to form a basis for making spectral shape adjustments to the ${ }^{235} U$ thermal fission field neutron spectrum. Figure 6 shows that if only the 15 Category I reactions (for which we have measurements in this field) are used in the least squares analysis, the resulting energy-dependent spectrum uncertainty is very significantly reduced while the chi-squared is 0.55 . The small chisquared is results from the pre-selection of consistent reaction data.

The ${ }^{56} \mathrm{Fe}(\mathrm{n}, \mathrm{p}),{ }^{63} \mathrm{Cu}(\mathrm{n}, 2 \mathrm{n}),{ }^{237} \mathrm{~Np}(\mathrm{n}, \mathrm{f})$, and ${ }^{238} \mathrm{U}(\mathrm{n}, \mathrm{f})$ reactions were previously considered to be Category I reactions [15] but failed to meet the stringent criteria used here. ${ }^{238} U(n, f)$ fails to make the list, but only just. It has a $\mathrm{C} / \mathrm{E}$ that differs from unity by $1.8 \mathrm{SD}$ which exceeds the $1.5 \mathrm{SD}$ requirement. Part of this failure is driven by the very small $\mathrm{C} / \mathrm{E}$ uncertainty currently estimated for this reaction in the ${ }^{252} \mathrm{Cf}$ fission field, $1.76 \%$. The $\mathrm{C} / \mathrm{E}$ for the ${ }^{56} \mathrm{Fe}(\mathrm{n}, \mathrm{p})$ reaction differs from unity by 2.13 standard deviations, invalidating it from consideration as a Category I reaction. The ${ }^{63} \mathrm{Cu}(\mathrm{n}, 2 \mathrm{n})$ reaction has a cross section uncertainty component of $4.06 \%$ which just misses the "well-known" requirement of $4 \%$. The ${ }^{237} \mathrm{~Np}(\mathrm{n}, \mathrm{f})$ reaction has a cross section uncertainty component of $9.21 \%$, missing by far the "wellknown" requirement.

Other reactions that were previously considered to be potential Category I candidates in 1979 , include the ${ }^{115} \operatorname{In}\left(n, n^{\prime}\right)$ and ${ }^{59} \mathrm{Co}(\mathrm{n}, \gamma)$ reactions. The ${ }^{115} \mathrm{In}\left(\mathrm{n}, \mathrm{n}^{\prime}\right)$ reaction has a $\mathrm{C} / \mathrm{E}$ that differs from unity by $1.6 \mathrm{SD}$, just missing the "consistency" requirement of $1.5 \mathrm{SD}$. The ${ }^{59} \mathrm{Co}(\mathrm{n}, \gamma)$ reaction has an experimental measurement uncertainty of $5 \%$, exceeding the $4 \%$ measurement requirement. It also has a $4.71 \%$ cross section uncertainty, exceeding the $4 \%$ "well-known" requirement and its C/E exceeds unity by 1.89 SDs missing the "consistency".

In light of the observed deficiencies in some reactions which just miss the Category I requirements, the ${ }^{115} \operatorname{In}\left(n, n^{\prime}\right)$, ${ }^{56} \mathrm{Fe}(\mathrm{n}, \mathrm{p}),{ }^{63} \mathrm{Cu}(\mathrm{n}, 2 \mathrm{n})$, and ${ }^{238} \mathrm{U}(\mathrm{n}, \mathrm{f})$ reactions should be identified as good candidates for future Category I status. Another reaction that should be considered a potential Category I reaction is ${ }^{6} \mathrm{Li}(\mathrm{n}, \mathrm{X})^{4} \mathrm{He}$. This reaction only missed inclusion because activity data in the ${ }^{252} \mathrm{Cf}$ standard fission field were not currently available to these authors. This cross section is also used as an IAEA-recommended standard cross section for energies from thermal to $0.1-\mathrm{MeV}$. If we add the three "potential" Category I reactions for which we have data in the least squares analysis of the ${ }^{235} \mathrm{U}$ thermal fission field, we have a chi-squared per degree of freedom of 0.51 with 18 degrees of freedom. 
The only significant problem with the new Category I selection, and it is a serious one, is the omission of ${ }^{237} \mathrm{~Np}(\mathrm{n}, \mathrm{f})$. The case of ${ }^{237} \mathrm{~Np}(\mathrm{n}, \mathrm{f})$ is significant because of its importance for the critical energy range from a few hundred $\mathrm{keV}$ up to 2 $\mathrm{MeV}$. The only Category I reactions that cover this range well are ${ }^{93} \mathrm{Nb}\left(\mathrm{n}, \mathrm{n}^{\prime}\right)$, which has a sensitivity far too low for fields used for electronics testing, and ${ }^{103} \mathrm{Rh}\left(\mathrm{n}, \mathrm{n}^{\prime}\right)$, which has good sensitivity (short half life product) but which is seldom used because of the difficult measurement of the low energy of the photons from the reaction product. The ${ }^{235} \mathrm{U}$ and ${ }^{239} \mathrm{Pu}$ fission reactions within ${ }^{10} \mathrm{~B}$ filters lack benchmark testing in the ${ }^{252} \mathrm{Cf}$ field.

In addition to its important energy range, ${ }^{237} \mathrm{~Np}$ has been considered to be a good Category I reaction for many years. This is because previous classifications were based on calculations that did not include the uncertainty in the cross section file, reflected in Table 1 by the large, $9.2 \%$, uncertainty in the ${ }^{252} \mathrm{Cf}$ spectrum. This uncertainty does seem justified in view of large discrepancies that can be found both in measured energydifferential data and in different evaluations. Other authors [17] have noted the large systematic scatter in the ${ }^{237} \mathrm{~Np}(\mathrm{n}, \mathrm{f})$ data. Despite the large uncertainty, the agreement in the C/E ratio is very good, as has often been noted before. This fact has prevented the problem of the large underlying cross section uncertainty from being exposed.

At least one high-quality energy-dependent measurement of the ${ }^{237} \mathrm{~Np}(\mathrm{n}, \mathrm{f})$ cross section [18] has been completed since the last evaluation, and therefore it appears to be a high priority to have a new evaluation performed for this important reaction. An adjustment of the cross section on the basis of benchmark field data should also be considered.

\section{CONCLUSION}

This work has provided the first detailed least squares analysis for the ${ }^{235} \mathrm{U}$ fission benchmark field and has updated the Mannhart analysis for the ${ }^{252} \mathrm{Cf}$ fission benchmark field. The adjustment in the benchmark spectra is presented. This analysis also provides the first detailed covariance matrix for the ${ }^{235} \mathrm{U}$ fission field. These data should be used to update the uncertainty section in several ASTM standards which discuss the use of activation foils and benchmark fields. Suggestions are made on how to revise previous recommendations for some nuclear data and on the need to confirm or re-evaluate other data.

A new list of Category I reactions is presented. Inclusion, for the first time, of a full analysis of the uncertainties in the spectrum averaged cross sections makes this list more soundly based than any previous one. It should be used in the revision of the applicable ASTM Standards that specify how to select dosimeters for neutron spectrum determination. A serious problem of the large uncertainty in the ${ }^{237} \mathrm{~Np}(\mathrm{n}, \mathrm{f})$ cross section is exposed here. A new evaluation of this important dosimetry reaction cross section is urgently needed.

\section{REFERENCES}

[1] P. J. Griffin, "Comparison of Calculated and Experimental Dosimetry Activities for Benchmark Neutron Fields," Proceedings of the Ninth International Symposium on Reactor. Dosimetry, held in Prague, Czech Republic, on September 2-6, 1996, World Scientific, 1997.

[2] Neutron Cross Sections for Reactor Dosimetry IAEA, Laboratory Activities, 1978, Vol. 1, p. 62.

[3] 1997 Annual Book of ASTM Standards, Vol. 12.02. Nuclear (II). Solar, and Geothermal Energy, ASTM, Philadelphia, 1997.

[4] W. Mannhart, Handbook on Nuclear Activation Data, IAEA, Tech. Report Series \#273, 1987.

[5] P. J. Griffin, J. G. Kelly, T. F. Luera, J. VanDenburg, SNL RML Recommended Dosimetry Cross Section Compendium, Sandia National Laboratories, Albuquerque, NM, report SAND92-0094, Aug. 1993.

[6] D. G. Madland, Theory of Neutron Emission in Fission, Los Alamos National Laboratory, report LA-UR-889-1747, 1989.

[7] M. Vlasov, IAEA Program on Benchmark Neutron Fields Applications for Reactor Dosimetry, Report INDC(SEC)-54/ L+Dos., IAEA, Vienna, 1976.

[8] M. Vlasov, IAEA Consultants' Meeting on Integral Cross Section Measurements in Standard Neutron Fields, Summary report. Conclusions and Recommendations, Report INDC(NDS) -81/L+Dos., IAEA, Vienna, 1977.

[9] F. W. Stallman, LSL-M2: A Computer Program for LeastSquares Logarithmic Adjustment of Neutron Spectra, NUREG/ CR-4349, ORNL/TM-9933, March 1985.

[10] International Reactor Dosimetry File (IRDF-90), N. P. Kocherov et al., IAEA, IAEA-NDS-141 Rev. 2, Oct. 1993.

[11] RSICC Data Library DLC-177, MATSX11 80-group Neutron. 24-Group Photon Cross Sections from ENDF/B-VI in MATXS Format, ORNL, Oak Ridge, TN, February 1994.

[12] ENDE-201. ENDF/B-VI Summary Documentation, edited by $P$. F. Rose, Brookhaven National Laboratory Report BNL-NCS$1741,4^{\text {th }}$ Edition, October 1991.

[13] C. Y. Fu, D. M. Hetrick, Proceedings of the Fourth ASTMEuratom Symposium on Reactor Dosimetry: Radiation Metrology Techniques, Data Bases, and Standardization. Volume II, US Nuclear Regulatory Commission, Wash. DC, Report NUREG/CP-0029, pp. 877-887.

[14] M. Petilli, D. Gilliam, in Reactor Dosimetry, Vol. 2, eds. J. P Genthon and H. Rottger, Reidel Publishing Company, Dordrecht, 1985, pp. 657-665.

[15] W. L. Zijp, J. H. Baard, Nuclear Data Guide for Reactor Neutron Metrology, Part 1: Activation Reactions, 1979 edition, Netherland Research Foundation, ECN-70, August 1979, pp. 145.

[16] W.L. Zijp, Proceedings of the Advisory Group Meeting on Nuclear Data for Reactor Dosimetry, Report ECN-78-163, IAEA, Vienna, May, 1979, pp. 187-219.

[17] A. A. Goverdovskij, Nuclear Standard Reference Data, Proceedings of An Advisory Group Meeting, Report IAEATECDOC-335, IAEA, Vienna, 1985, pp. 465-466.

[18] A. D. Carlson, et al., Reactor Dosimetry, ASTM STP 1228, ed. H. Farrar, et al., ASTM, Philadelphia, 1994, pp. 704-710. 